\title{
Watershed Scale Response to Climate Change-Pomperaug River Watershed, Connecticut
}

\section{Introduction}

General Circulation Model (GCM) simulations of future climate through 2099 project a wide range of possible scenarios (Intergovernmental Panel on Climate Change, 2007). To determine the sensitivity and potential effect of long-term climate change on the freshwater resources of the United States, the U.S. Geological Survey Global Change study, "An integrated watershed scale response to global change in selected basins across the United States" was started in 2008. The long-term goal of this national study is to provide the foundation for hydrologically based climate-change studies across the nation.

Fourteen basins for which the Precipitation Runoff Modeling System (PRMS) has been calibrated and evaluated were selected as study sites. PRMS is a deterministic, distributedparameter watershed model developed to evaluate the effects of various combinations of precipitation, temperature, and land use on streamflow and general basin hydrology. Output from five General Circulation Models and four emission scenarios were used to develop an ensemble of climate-change scenarios for each basin. These ensembles were simulated with the corresponding PRMS model. This fact sheet summarizes the hydrologic effect and sensitivity of the PRMS simulations to climate change for the Pomperaug River Basin at Southbury in Connecticut (U.S. Geological Survey streamflow-gaging station 01204000; fig. 1) presented in the project summary report (Markstrom and others, 2012) and journal article (Hay and others, 2011).

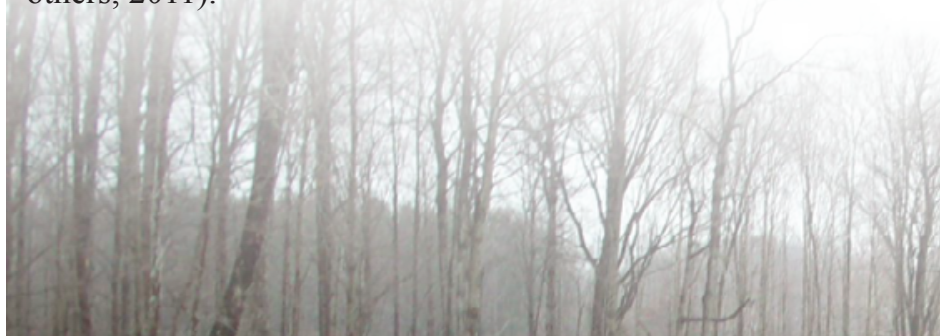

\section{Study Area}

The Pomperaug River Basin is located in western Connecticut and covers an area of about 194 square kilometers $\left(\mathrm{km}^{2}\right)$ and ranges in elevation from 63 to 332 meters. The river flows into the Housatonic River which is a tributary to the Long Island Sound. The basin supports significant areas of groundwater withdrawal for commercial and industrial use. Withdrawals for agricultural use mostly come from surface water. Portions of eight towns are included within the basin boundary. Land use and land cover in the basin have changed over the last century from primarily agriculture to primarily forest with an increasing, but still relatively small, percentage of urban and residential use.

In recent years, increased use of surface- and groundwater supplies in the Pomperaug River Basin has created concern that insufficient flows remain for future development, aquatic habitat, and recreational use. In response, the Pomperaug River Watershed Coalition (PRWC) was formed. Stakeholders in the basin identified a need to determine the amount of water available for future allocation while protecting the ecological integrity of the basin. Although the basin is rural, the population increased by 15 percent during the last decade as a result of suburban growth. Increases in population and development can lead to changes in land use and land cover that may cause changes in the distribution of runoff and groundwater recharge. Unless these cumulative effects are considered when allocating the water resources, instream flow losses and degradation of water quality and ecosystems can occur. Because of uncertainty about the quantity of water available for future use, the effects of new applications for water diversion are poorly understood. The U.S. Geological Survey, in cooperation with the Pomperaug River Watershed Coalition (PRWC), developed a PRMS model for the Pomperaug River as part of a study to evaluate the potential effects of land-use change and water management strategies on streamflow, instream habitat, and groundwater availability in the Pomperaug River Basin (Bjerklie and others, 2010).

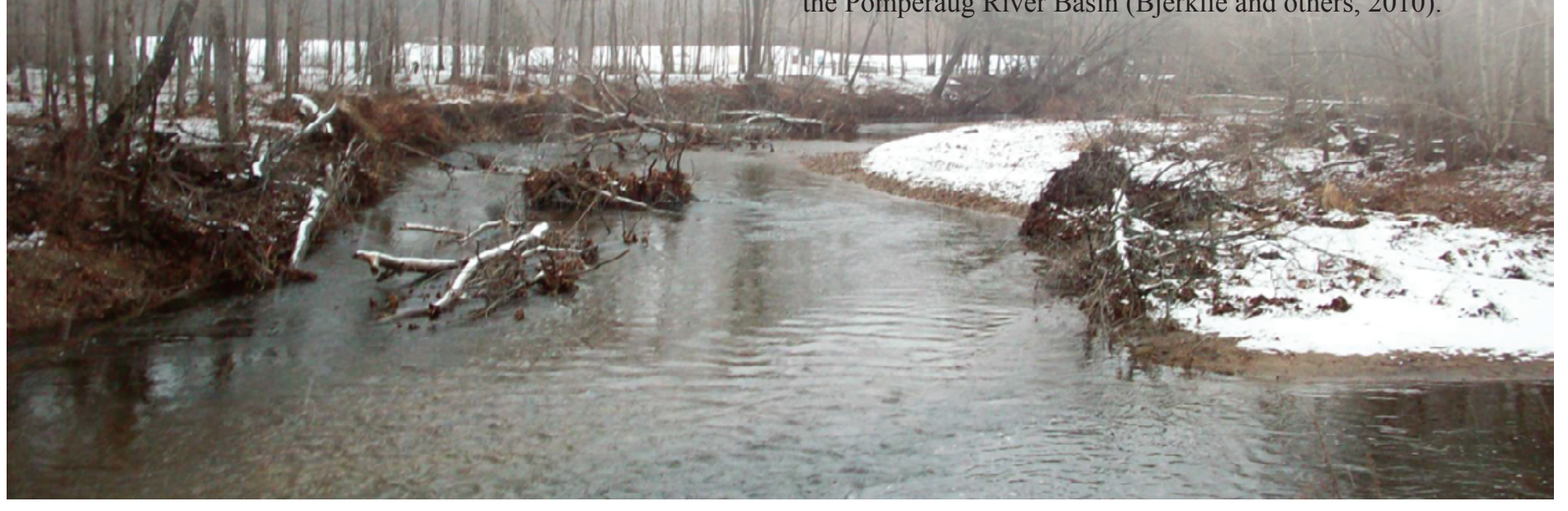



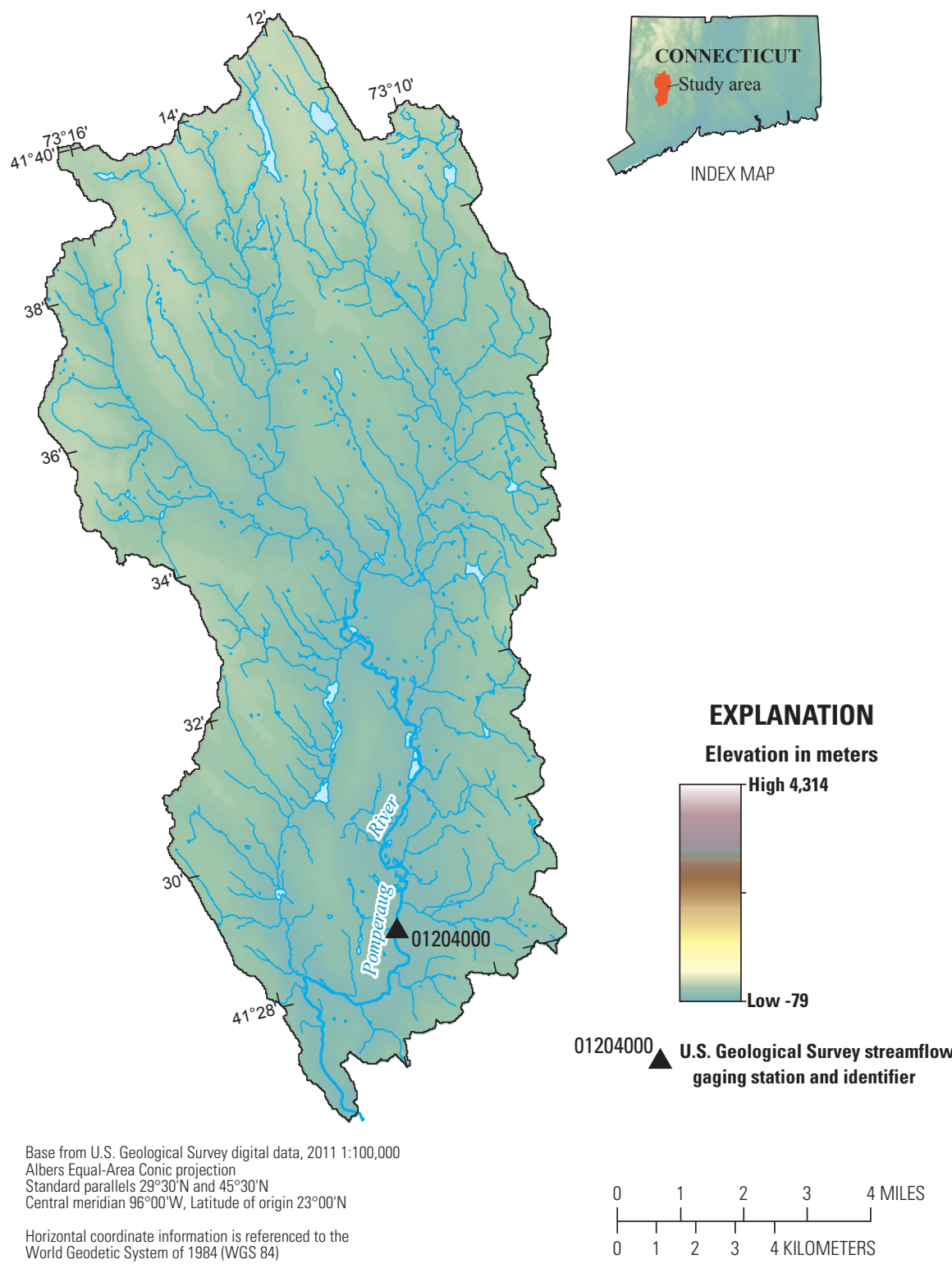

Figure 1. Precipitation Runoff Modeling System study locations, Pomperaug River Basin, Connecticut, and location of U.S. Geological Survey streamflow-gaging station 01204000 with a drainage area of 194 square kilometers and elevation range from 63 to 332 meters.

\section{General Circulation Models}

Given the uncertainty in climate modeling, it is desirable to use more than one GCM to obtain a range of potential future climatic conditions. Monthly precipitation and temperature output from five GCMs were processed (table 1).

Table 1. General Circulation Model (GCM) projections used in this study.

\begin{tabular}{ll}
\hline \multicolumn{1}{c}{ GCM } & \multicolumn{1}{c}{ Center and country of origin } \\
\hline BCC-BCM2.0 & Bjerknes Centre for Climate Research, Norway \\
CSIRO-Mk3.0 & Australia's Commonwealth Scientific and Industrial Research Organization, Australia \\
CSIRO-Mk3.5 & Australia's Commonwealth Scientific and Industrial Research Organization, Australia \\
INM-CM3.0 & Institute for Numerical Mathematics, Russia \\
MIROC3.2 & National Institute for Environmental Studies, Japan \\
\hline
\end{tabular}


The GCM outputs were obtained from the World Climate Research Programme's Coupled Model Intercomparison Project phase 3 multi-model dataset archive, which was referenced in the Intergovernmental Panel on Climate Change Fourth Assessment Special Report on Emission scenarios (Intergovernmental Panel on Climate Change, 2007). For each GCM, one current (water years 1988-1999) and three future emission scenarios were used and are described in table 2.

Table 2. Climate-change emission scenarios simulated by the General Circulation Models in this study.

\begin{tabular}{ll}
\hline \multicolumn{1}{c}{ Emission scenario } & \multicolumn{1}{c}{ Description/assumptions } \\
\hline 20C3M & $\begin{array}{l}\text { 20th century climate used to determine baseline (1989-1999) conditions } \\
\text { Rapid economic growth, a global population that peaks in mid-21st century and rapid introduction of new and } \\
\text { more efficient technologies with a balanced emphasis on all energy sources } \\
\text { Convergent world, with the same global population as Emission scenario A1B, but with more rapid changes in } \\
\text { economic structures toward a service and information economy that is more ecologically friendly } \\
\text { A2 }\end{array}$ \\
\hline
\end{tabular}

Climate-change fields were derived by calculating the change in climate from current (water years 1988-1999) to future conditions simulated by each GCM. The 20C3M simulation for water years 1988-1999 was used to represent current climatic conditions. This 12-year period of record was chosen based on the overlap of the available historical records from the 14 basins included in the national study. Climate change fields (percentage changes in precipitation and degree changes in temperature) were computed for 12-year moving window periods (from 2001-2099) using the 20C3M (1988-1999) and the A1B, B1, and A2 emission scenarios. A 12-year moving window, starting in 2001 and ending in 2099, results in 1,320 future scenarios $[(88,12$-year climatologies, 1 per year starting with 2001-2012 and ending with 2088-2099) x (3 emission scenarios) $\mathrm{x}$ (5 GCMs)].

Climate-change scenarios were generated for PRMS by modifying PRMS precipitation and temperature inputs with the mean monthly climate change fields derived from the GCMs, resulting in 1,320 PRMS-input files. Table 3 shows the change (slope) and adjusted $\mathrm{R}^{2}(\operatorname{adj} \mathrm{R} 2)$ for the least squares fit to the trend line for selected output variables from the PRMS projections. The slope indicates the change in the selected variable by year. The adjusted $\mathrm{R}^{2}$ value gives an indication of the variability in the central tendency of the trend line.

Figure 2 shows a summary of the projected range in 11-year moving mean daily values of maximum temperature (fig. $2 A$ ), minimum temperature (fig. $2 B$ ), and precipitation (fig. $2 C$ ) by emission scenario. The first year of each 12-year simulation was used as PRMS initialization and is not included in the results. The 3 solid-lines indicate the 11-year moving mean values (x-axis indicates center of 11-year window) for the three future emission scenarios (central tendency of the five GCMs for each emission scenario). The projected range shown for each emission scenario indicates the range of potential future climatic conditions simulated by the five GCMs. All GCM simulations project an overall steady increase in maximum and minimum temperature (table 3), with uncertainties associated with these GCM projections increasing with time. Both maximum and minimum temperatures show the smallest projected changes for the B1 emission scenario. Projections of mean annual precipitation for the Pomperaug Basin highly are variable, with the B1 emission scenario showing a slight positive trend in the central tendency (table 3). The wide range in the precipitation projections indicates a large amount of uncertainty with relatively large year to year variation.

\section{Results}

PRMS simulates spatially distributed streamflow, components of flow (surface, subsurface, and groundwater), snowpack conditions, and many other hydrologic components of interest. Streamflow, groundwater recharge, and snowmelt are of particular interest because changes in these variables may directly affect human activities and instream habitat. Figure 3 shows the projected range in 11-year moving mean daily values of streamflow (fig. $3 A$ ), groundwater recharge (fig. $3 B$ ), and snowmelt (fig. $3 C$ ) by emission scenario. The uncertainties associated with the streamflow projections are large. The central tendency of the five GCMs projects a significant decrease in mean annual streamflow for the A2 emission scenario only (table 3). Groundwater recharge shows a more marked decrease over time for the A1B and A2 emission scenarios (table 3), with wide year-to-year variability and large uncertainty. Snowmelt is projected to steadily decline with less uncertainty and is consistent across all three emission scenarios (table 3).

Projected changes in hydrologic variables also can be examined on a monthly basis (figs. 4 and 5). The solid dark red lines show PRMS-simulated mean monthly baseline conditions (1989-1999). The boxplots represent the range in the mean monthly outputs for the five GCMs and three emission scenarios for 2030 (green, 2025-2035), 2060 (tan, 2055-2065) and 2090 (blue, 2085-2095). Figure 4 shows the monthly summary of PRMS-simulated basin mean daily values of evapotranspiration (fig. 4A) and soil moisture (fig. $4 B$ ) for baseline conditions and the three projected time periods. Evapotranspiration is projected to increase in every month and on an annual basis (table 3 ). 

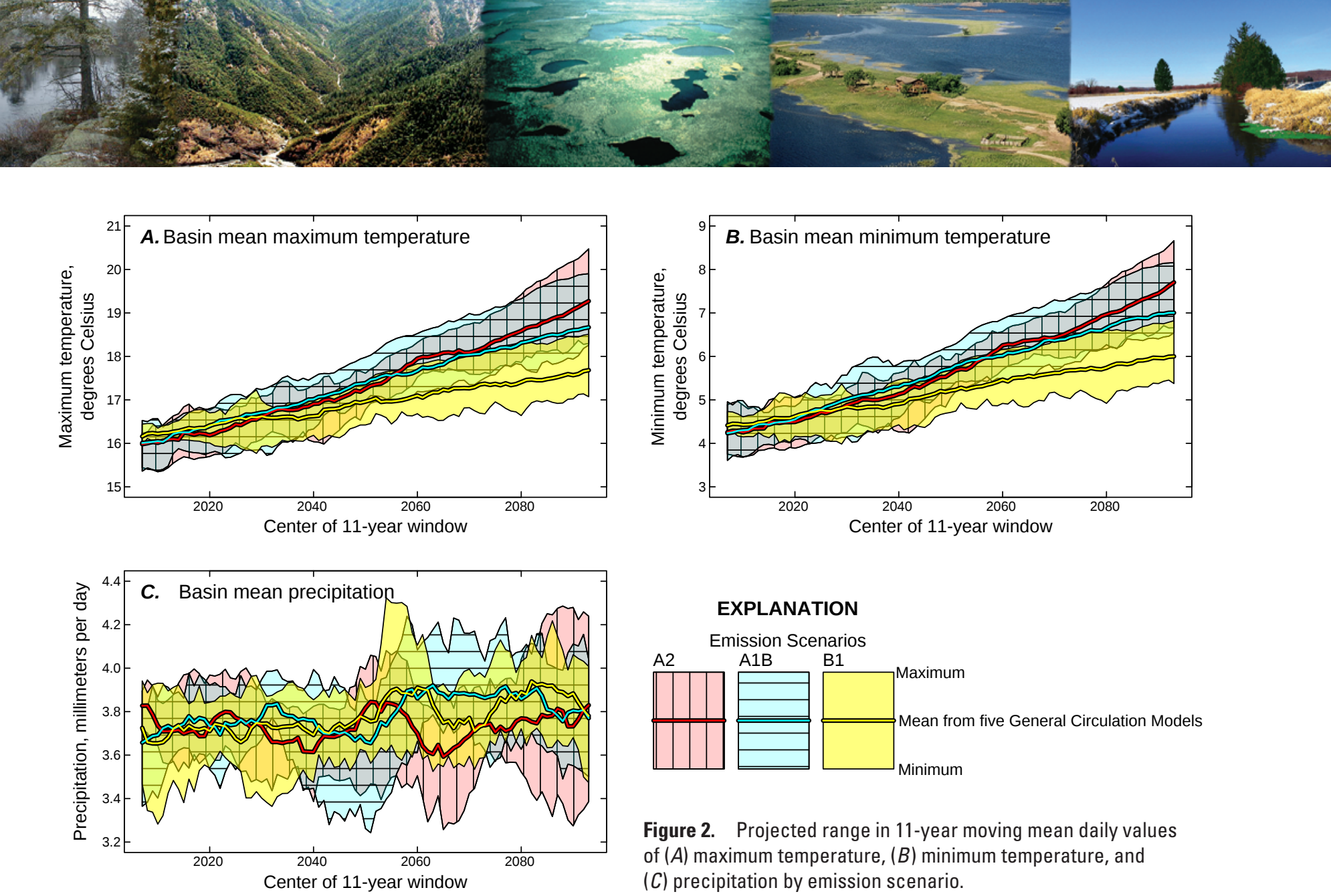

Figure 2. Projected range in 11-year moving mean daily values of $(A)$ maximum temperature, $(B)$ minimum temperature, and (C) precipitation by emission scenario.

Table 3. Projected change by year (slope) and adjusted $R^{2}$ (adjR2) based on the central tendencies of the five General Circulation Models for the three carbon emission scenarios for selected Precipitation Runoff Modeling System (PRMS) output variables.

[Blue indicates a significant negative trend and yellow indicates a significant positive trend $(\mathrm{p}<0.05)$ accounting for lag-1 autocorrelation]

\begin{tabular}{|c|c|c|c|c|c|c|}
\hline \multirow[t]{2}{*}{ PRMS output variable } & \multicolumn{2}{|c|}{$\begin{array}{c}\text { Emission scenario } \\
\text { A1B } \\
\end{array}$} & \multicolumn{2}{|c|}{$\begin{array}{c}\text { Emission scenario } \\
\text { A2 }\end{array}$} & \multicolumn{2}{|c|}{$\begin{array}{c}\text { Emission scenario } \\
\text { B1 } \\
\end{array}$} \\
\hline & slope & adjR2 & slope & adjR2 & slope & adjR2 \\
\hline Maximum temperature in degrees Celsius & 0.032 & 1.00 & 0.039 & 0.99 & 0.017 & 0.99 \\
\hline Minimum temperature in degrees Celsius & 0.034 & 1.00 & 0.040 & 0.99 & 0.019 & 0.99 \\
\hline Precipitation in millimeters per day & 0.0019 & 0.38 & 0.0002 & -0.00 & 0.0024 & 0.57 \\
\hline Evapotranspiration in millimeters per day & 0.0045 & 0.99 & 0.0053 & 0.99 & 0.0029 & 0.99 \\
\hline Streamflow in cubic meters per second & -0.0061 & 0.59 & -0.0116 & 0.82 & -0.0012 & 0.05 \\
\hline Snowmelt in millimeters per day & -0.0040 & 0.96 & -0.0053 & 0.98 & -0.0025 & 0.94 \\
\hline Groundwater recharge in millimeters per day & -0.0025 & 0.79 & -0.0040 & 0.89 & -0.0008 & 0.36 \\
\hline Soil moisture in millimeters per day & -0.1650 & 0.95 & -0.2205 & 0.93 & -0.0534 & 0.64 \\
\hline
\end{tabular}

Soil moisture is projected to decrease in every month and on an annual basis (table 3 ), with the largest decreases occurring in the summer months (July through September) when potential evapotranspiration is highest.

Monthly projections of streamflow are shown in figure 5 for the 11-year periods centered on 2030, 2060, and 2090.
Streamflow is projected to decrease in all months with the exception of January, which is the only month that snowmelt is not projected to decrease (not shown). The wide range of values indicated by the boxplots in figure 5 illustrates the high degree of uncertainty associated with the magnitude of these projected streamflow changes. 

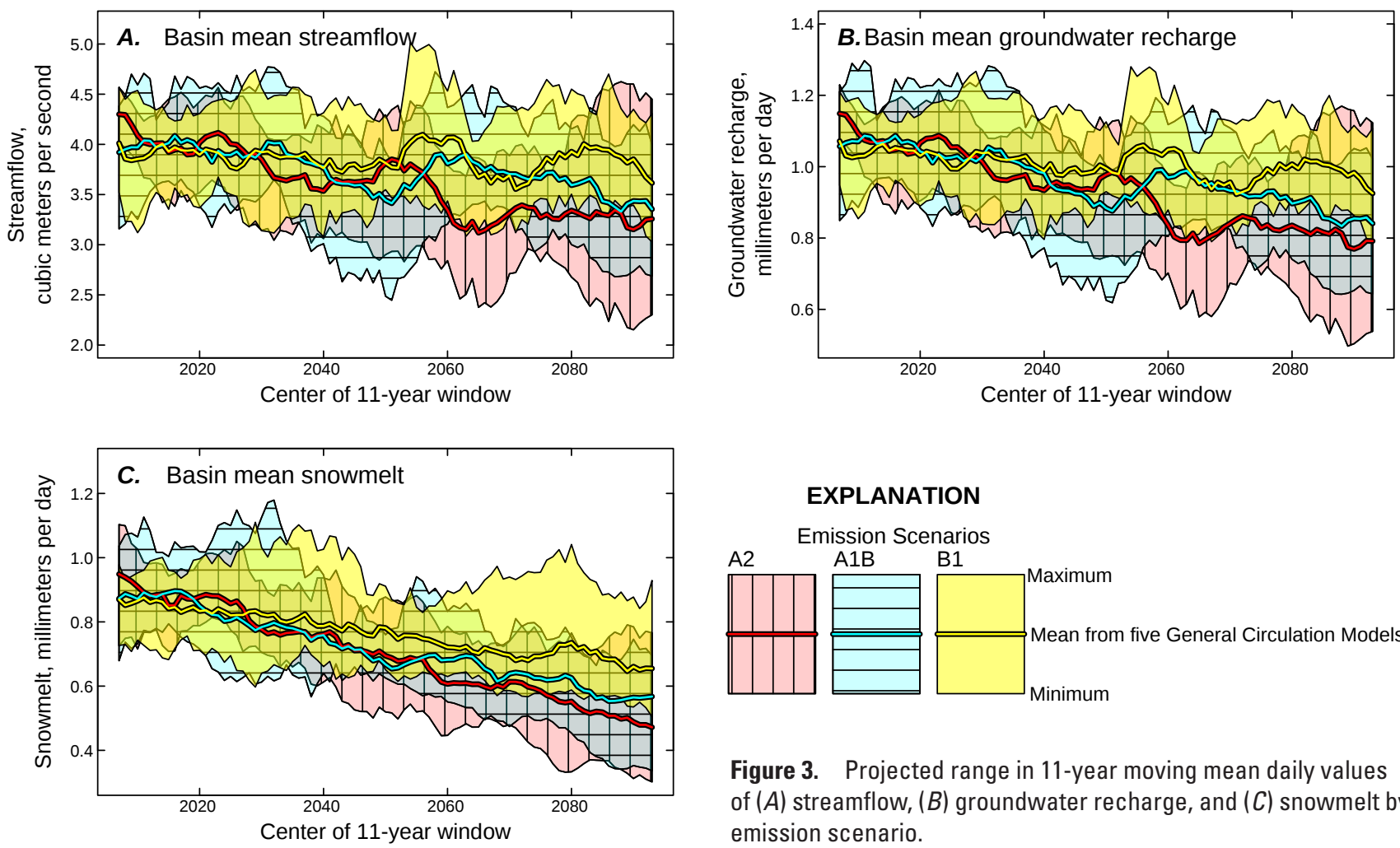

\section{EXPLANATION}

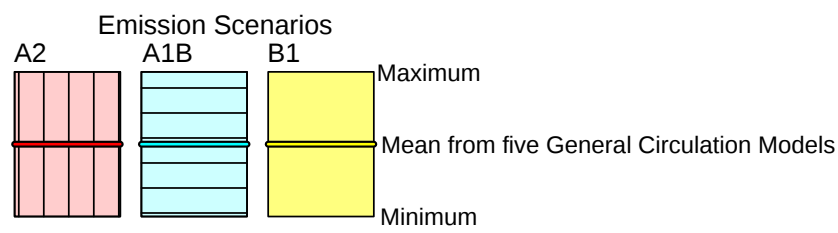

Figure 3. Projected range in 11-year moving mean daily values of $(A)$ streamflow, $(B)$ groundwater recharge, and $(C)$ snowmelt by emission scenario.
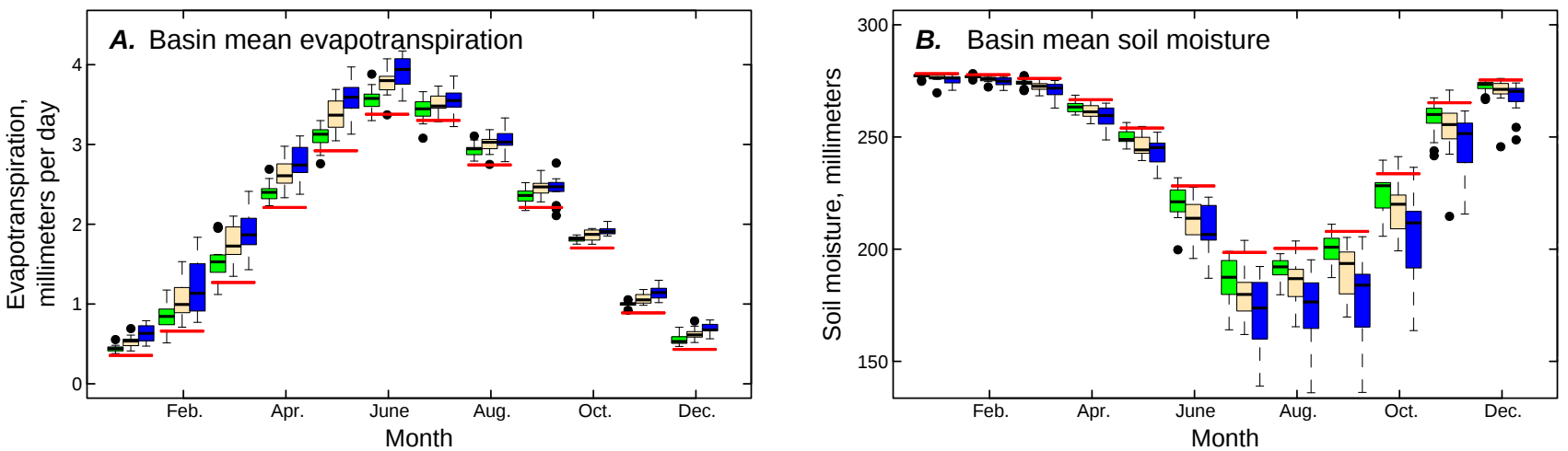

Figure 4. Mean daily $(A)$ evapotranspiration and $(B)$ soil moisture values by month for baseline conditions and projected range (2030, 2060, and 2090) using the five General Circulation Models and three emission scenarios.
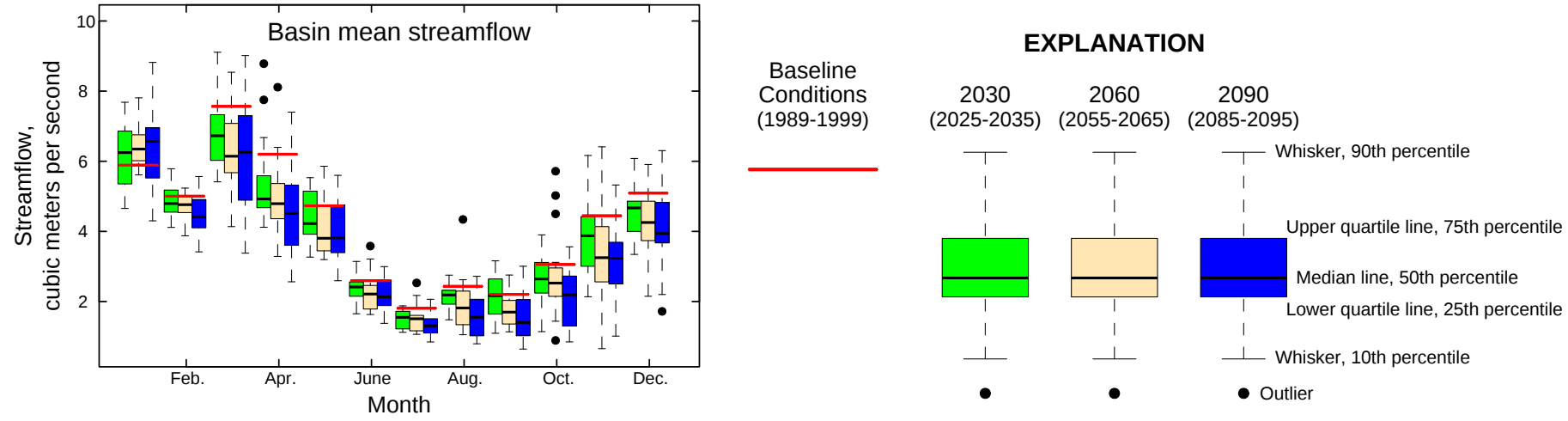

Figure 5. Mean daily streamflow values by month for baseline conditions and projected range $(2030,2060$, and 2090) using the five General Circulation Models and three emission scenarios. 
